\title{
Synthesis of Conductive Nano Ink Using 1-Octanethiol Coated Copper Nano Powders in 1-Octanol for Low Temperature Sintering Process
}

\author{
Jaehak Her, Danee Cho and Caroline Sunyong Lee* \\ Department of Materials Engineering, Hanyang University, 55 Hanyang daehak-ro, Sangnok-gu, Ansan-si, \\ kyeonggi-do 426-791, Republic of Korea
}

\begin{abstract}
A conductive nanoink was prepared using copper nanoparticles (CNPs). In order to prevent the oxidation of CNPs, the particles were coated by 1-octanethiol using Vaporized Self-Assembled Multi-layers (VSAMs) method. The coating of 1-octanethiol onto CNPs was confirmed by transmission electron microscope (TEM) and X-ray photoelectron spectroscopy (XPS). Dispersion stability of CNPs was checked by monitoring its viscosity over 6 weeks. The sheet-type of patterned samples using the fabricated ink was sintered at 350 and $230^{\circ} \mathrm{C}$, respectively. Electrical resistivity was measured to be $5.69 \times 10^{-8} \Omega \cdot \mathrm{m}$ when sintered at $350^{\circ} \mathrm{C}$ and $7.67 \times 10^{-8} \Omega \cdot \mathrm{m}$ when sintered at $230^{\circ} \mathrm{C}$. These results were 3.4 and 4.6 times than the value for bulk copper. During the sintering process, the optimum temperature of removing organic materials was found to be $200^{\circ} \mathrm{C}$. This removal temperature dramatically influenced necking and the density of samples. Therefore, 1-octanethiol VSAMs and 1-octanol ink were used successfully for the low-temperature sintering process to fabricate conductive $\mathrm{Cu}$ patterns by finding the optimum temperature of $200^{\circ} \mathrm{C}$ for complete removal of organic materials prior to the sintering process. [doi:10.2320/matertrans.M2012363]
\end{abstract}

(Received October 30, 2012; Accepted January 18, 2013; Published March 1, 2013)

Keywords: inkjet, copper, 1-Octanethiol coating, 1-Octanol

\section{Introduction}

Recently, patterning technologies have been developed to overcome issues with photolithography, as demand for transparent, low-cost substrates for flexible displays and devices increases. Screen printing, nano-imprinting, jet printing and direct printing technology are emerging patterning field technologies to replace conventional photolithography. ${ }^{1-7)}$ Photolithograpy, one of the most widely used in semiconductor process, has been developed by many researchers for mass production. However, it requires toxic chemicals and consists of many fabrication processes, resulting huge material loss. Therefore, many researchers have studied alternative process to solve these problems. The inkjet printing process has much less fabrication processes and also it does not require toxic chemicals. And inkjet printing technology can be used in Radio-Frequency Identification (RFID), Printed Circuit Board (PCB), display, solar cell, bio products and so on. ${ }^{8-12)}$ The copper powders used in inkjet technology for line patterning, are focused in this study, because of its high electrical and thermal conductivity and low cost. However, using nano sized copper powders for a ink has a critical disadvantage of easy oxidation in air.

To overcome this problem, copper nanopowder synthesis in wet solution was used widely but it requires long processing time and toxic materials. ${ }^{13)}$ These nanopowders need to be in non-oxidizing environment before sintering. In this study, the dry coating Vaporized Self-Assembled Multi-layers (VSAMs) method is employed to remedy weaknesses of wet method. Also it can be used for in-situ process with dry powder making method. 1-otanethiol $\left(\mathrm{CH}_{2}\left(\mathrm{CH}_{3}\right)_{7} \mathrm{SH}\right)$, one of the alkanethiol $\left(\mathrm{CH}_{2}\left(\mathrm{CH}_{3}\right)_{n} \mathrm{SH}\right)$, is used for dry coating method. It is coated on the surface of CNPs for oxidation prevention as long as fresh metal surface is exposed to bond with Sulfur which is at the end of

*Corresponding author, E-mail: sunyonglee@ hanyang.ac.kr 1-octanethiol chain. It has been studied that the oxidation prevention layers formed by $\mathrm{Cu}-\mathrm{S}$ bonding can protect from oxidation for 35 days. ${ }^{7,14,15)}$ Coating thickness of 1octanethiol layers is controlled from 4 to $10 \mathrm{~nm}$ by varying experimental parameters. ${ }^{7)}$ Moreover, 1-Octanethiol can be easily removed before sintering copper because it has a burnoff temperature at $197^{\circ} \mathrm{C}$. Therefore, copper particles are protected from oxidation until sintering step is completed.

1-octanol, which has a similar molecular structure as that for 1-octanethiol, was used as a solvent for stability of dispersion. It can be easily removed during sintering because it has a low flash point of $80^{\circ} \mathrm{C}$ and a boiling point of $196^{\circ} \mathrm{C}$. The aliphatic chain group like 1-octanethiol and 1-octanol can have a polarity or apolarity with their $\mathrm{CH}_{3}$ chain length. 1-octanethiol and 1-octanol have enough chain length for being non-polar for good dispersion. Therefore, 1-octanol was considered to be a good solvent for copper powders coated by 1-octanethiol to be dispersed like mixing of non-polar liquid. Studies done by Haque et al. investigated sintering mechanism of Vapor Self-Assembled Multilayer coated $\mathrm{Cu}$ nanoparticles (CNPs) at a relatively high temperature which is $350^{\circ} \mathrm{C} .{ }^{16)}$ In this paper, optimized sintering process of nanoink at low temperature was reported with respect to investigating complete removal temperature of organic materials prior to sintering.

\section{Experiment Procedure}

CNPs with an average diameter of $100 \mathrm{~nm}$, are synthesized by polyol method. ${ }^{14)}$ The coating was done using the equipment as shown in Fig. 1. When the vaccum chamber reaches set-point $(2.67 \mathrm{~Pa}), 1$-octanethiol vapor goes into chamber and VSAMs are formed on the surface of copper nano powders which are not oxidized.

The fabricated ink consists of 10 mass $\%$ 1-octanethiol coated CNPs and 90 mass \% 1-octanol. The powders and solvent were placed into a bottle and then sonicated for $30 \mathrm{~min}$ for dispersion. The dimension of the sample was 


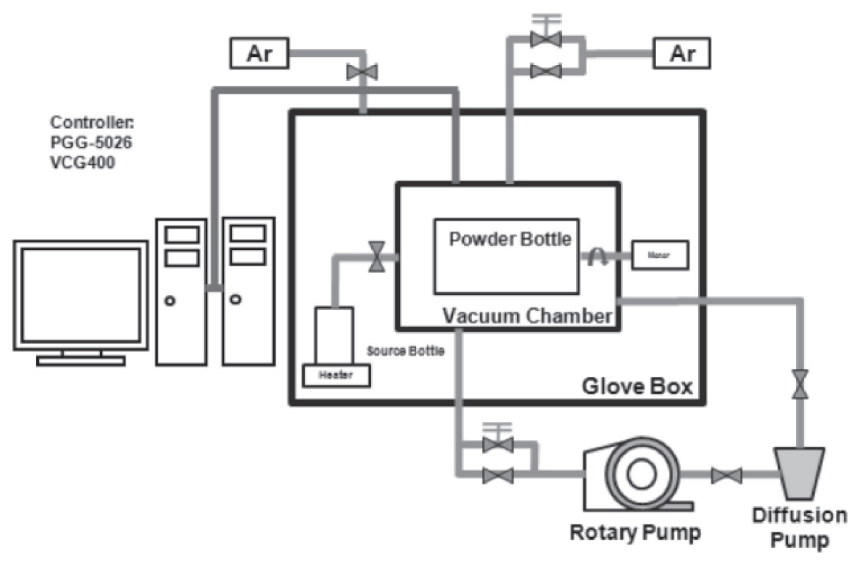

Fig. 1 Schematic of the 1-octanethiol coating equipment. ${ }^{14)}$

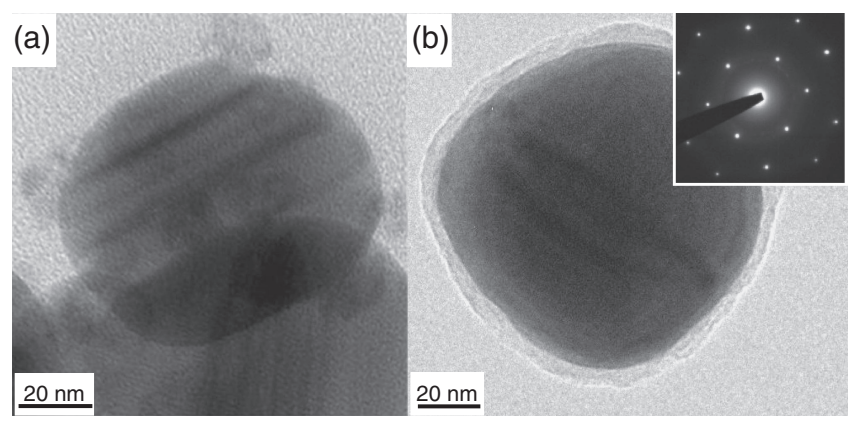

Fig. 2 TEM image of $\mathrm{Cu}$ powders (a) before coating and (b) after coating.

$10 \mathrm{~mm} \times 10 \mathrm{~mm}$ on slide glasses with $30 \mathrm{ul}$ of ink. The heattreatment was done in hydrogen gas $(99.999 \%$ purity) atmosphere with $5^{\circ} \mathrm{C} / \mathrm{min}$ of heating rate followed by $2^{\circ} \mathrm{C} / \mathrm{min}$ of cooling rate. During heating profile, intermediate step at $150^{\circ} \mathrm{C}$ for $1 \mathrm{~h}$ and at $200^{\circ} \mathrm{C}$ for $1 \mathrm{~h}$, were studied separately to investigate optimum temperature for removing organic materials such as 1-octanethiol and 1-octanol before sintering among $\mathrm{Cu}$ powders. The final sintering temperatures at $350^{\circ} \mathrm{C}$ for $4 \mathrm{~h}$ and at $200^{\circ} \mathrm{C}$ for $8 \mathrm{~h}$ were tested separately. The coating layers on the surface of $\mathrm{Cu}$ powders were confirmed by XPS and TEM analysis. Stability of dispersion was observed by viscometer (DV-II+ viscometer, Brook field). Electrical resistivity was measured using 4-point probe for sheet resistance and alpha-step for its thicknesses. Samples were observed using SEM. XPS and TG/DTA analyses to check for any residual organic materials after sintering.

\section{Results and Discussion}

Figure 2 shows TEM image of VSAMs coating with its thickness of $10 \mathrm{~nm}$ on the surface of non-oxidized CNPs. As shown in the Fig. 2, VSAMs were evenly coated on the surface of $100 \mathrm{~nm}$-sized $\mathrm{Cu}$ powders. To confirm that 1octanethiol was successfully bonded on the surface of $\mathrm{Cu}$ powders, XPS analysis was performed (Fig. 3), and at around $162 \mathrm{eV}$, a peak for $\mathrm{Cu}-\mathrm{S}$ bonding was successfully detected on the surface of CNPs. ${ }^{13-15)}$

To study how those powders were dispersed, viscometer was used. The initial viscosity of the ink was measured to be

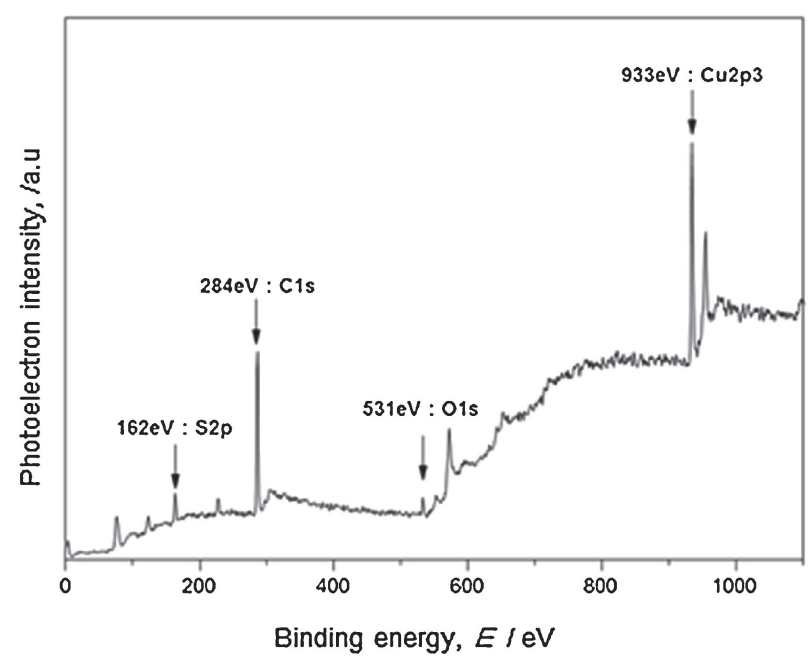

Fig. 3 XPS analysis of 1-octanethiol coated $\mathrm{Cu}$ powders.

Table 1 Viscosity results of ink solution with respect to time.

\begin{tabular}{cc}
\hline Weeks & Viscosity, /cPs \\
\hline 0 & 8.3 \\
3 & 8.3 \\
6 & 8.4 \\
\hline
\end{tabular}

$8.3 \mathrm{cP}$. After 6 weeks later, the change in viscosity of the ink is minimal. (Table 1) This result indicates the stable dispersion of the ink. The aliphatic chain group has its character of non-polarity as chain length becomes longer as 1-octanethiol which is coated on the copper powder also has non-polarity. Therefore, we assume that molecular similarity between 1-octanethiol and 1-octanol result in stability of dispersion. Methanol, ethanol and butanol were used for ink, but their period of dispersion was less than 1 day. This result means that chain length of molecule influences on dispersion as well as its similarity of molecular structure.

TG/DTA analysis was performed to study removal temperature of organic materials before sintering. Figure 4 shows its rapid decrease in mass of the ink at $80^{\circ} \mathrm{C}$ which is flash point of 1-octanol. At temperature less than $142^{\circ} \mathrm{C}$, mass reduction of the ink almost completed. After that, there is no mass reduction, indicating that the organic materials can be removed in the range of temperatures from 80 to $142^{\circ} \mathrm{C}$. This result agrees with Fig. 5 which shows XPS result of $\mathrm{Cu}$ powders after sintering; a peak at $162 \mathrm{eV}$ peak was not found. This indicates that there is no $\mathrm{Cu}-\mathrm{S}$ bonding and 1-octanethiol was successfully removed after sintering.

As show in Fig. 5, oxygen peak increased significantly. The sample was sintered while 1-octanethiol coating layer was removed with surface oxidation. The resistivity of the sample was observed in the range of $10^{-8}$ to $10^{-7} \Omega \cdot \mathrm{m}$ which confirms surface oxidation with no internal oxidation. Moreover, the amount of carbon which is $37.62 \mathrm{at} \%$, was detected. One might suspect that this carbon peak might be from residual 1-octanethiol. However, the study done by Kwon et al. showed that 29 at\% of carbon was detected in 


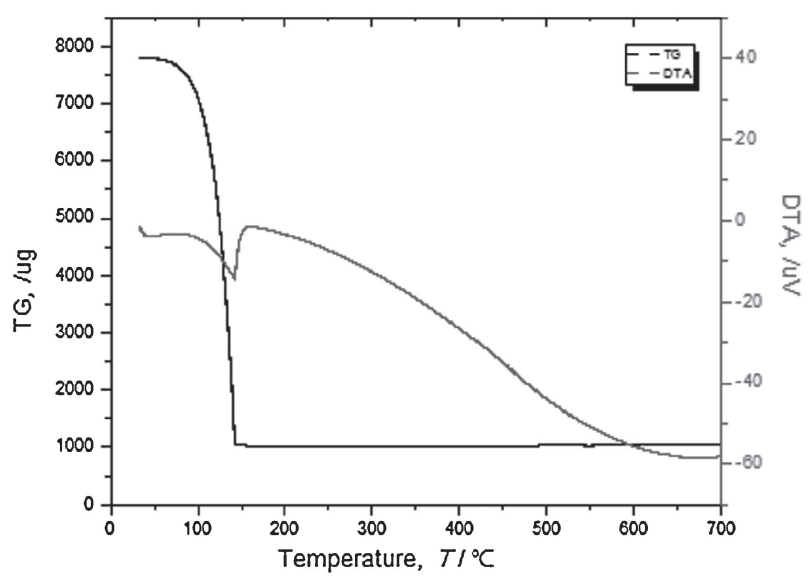

Fig. 4 TG/DTA analysis of $\mathrm{Cu}$ ink.

Table 2 XPS analysis of $\mathrm{Cu}$ surface with no 1-octanethiol coating followed by its exposure to air for 20 days. ${ }^{14)}$

\begin{tabular}{ccccc}
\hline Components & Carbon & Copper & Oxygen & Sulfur \\
\hline at $\%$ & 29 & 33 & 38 & 0 \\
\hline
\end{tabular}

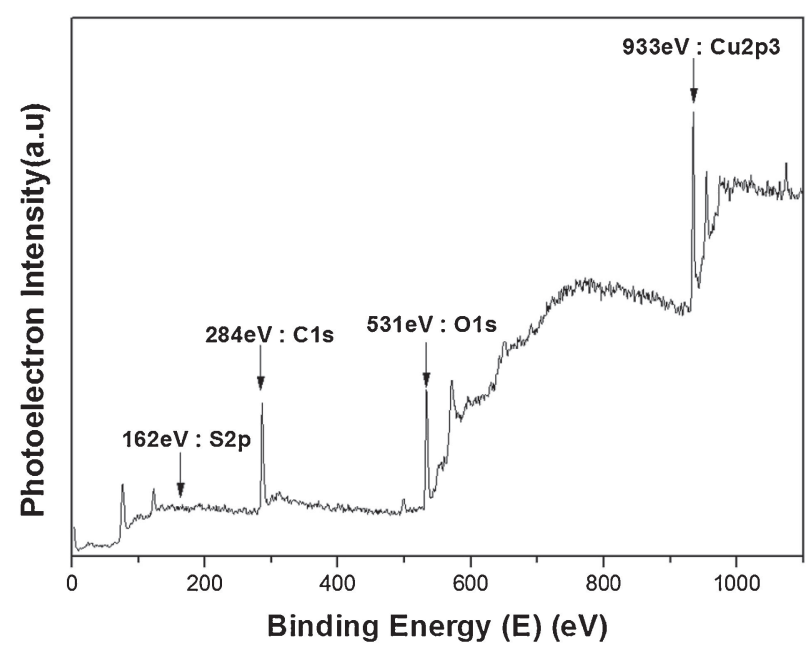

Fig. 5 XPS analysis of 1 -octanethiol coated $\mathrm{Cu}$ powders after sintering. This analysis shows that $\mathrm{Cu}-\mathrm{S}$ bonding disappeared after sintering, indicating that 1 -octanethiol and 1-octanol were removed successfully.

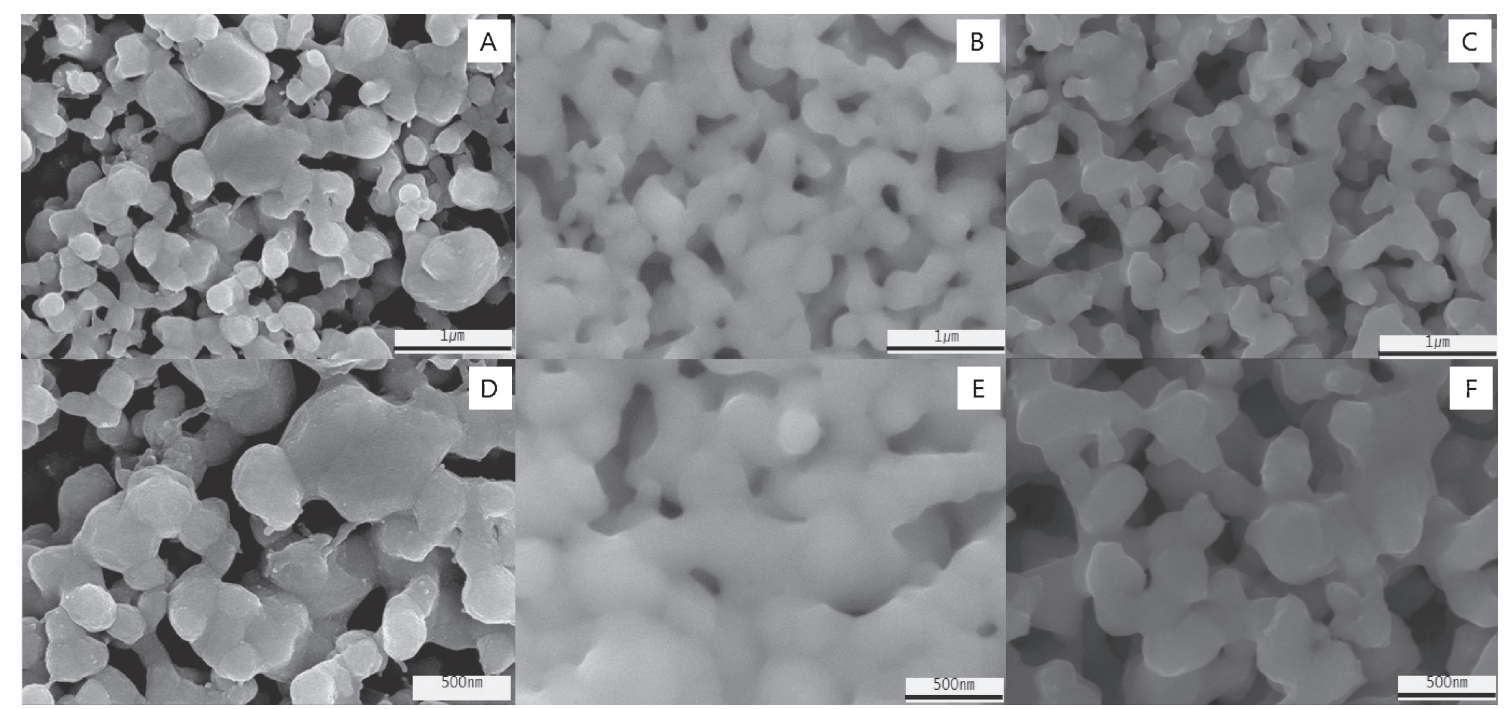

Fig. 6 SEM images of $\mathrm{Cu}$ powders after heat treatment at $150^{\circ} \mathrm{C}$ step- $350^{\circ} \mathrm{C}$ sintered (A) and (D), at $200^{\circ} \mathrm{C}$ step- $350^{\circ} \mathrm{C}$ sintered $(\mathrm{B})$ and (E), and at $200^{\circ} \mathrm{C}$ step $-230^{\circ} \mathrm{C}$ sintered (C) and (F).

$\mathrm{Cu}$ sample which was not coated with 1-octanethiol and oxidized for 20 days as shown in Table 2. ${ }^{7)}$ This amount of carbon in the air is quite similar to the amount of carbon detected after sintering, indicating that carbon peak detected after sintering is not due to residual 1-octanethiol on the surface of $\mathrm{Cu}$ powders, but due to carbon in the air. Absence of $\mathrm{Cu}-\mathrm{S}$ peak after sintering also confirms that the carbon peak is not due to residual 1-octanethiol but from the air.

The electrical resistivity of the sintered $\mathrm{Cu}$ powders with $150^{\circ} \mathrm{C}-1 \mathrm{~h}$ step followed by $350^{\circ} \mathrm{C}-4 \mathrm{~h}$ was measured to be $2.63 \times 10^{-7} \Omega \cdot \mathrm{m}$ and the electrical resistivity of the sintered sample with $200^{\circ} \mathrm{C}-1 \mathrm{~h}$ step followed by $350^{\circ} \mathrm{C}-4 \mathrm{~h}$ was measured to be $5.69 \times 10^{-8} \Omega \cdot \mathrm{m}$. From this result, having $200^{\circ} \mathrm{C}-1 \mathrm{~h}$ step results lower resistivity than the sample with $150^{\circ} \mathrm{C}-1 \mathrm{~h}$ step. TG/DTA result indicated that the organic materials can be removed under $150^{\circ} \mathrm{C}$. However, the removal speed of organic materials depends on temperature, influencing its resistivity. Figure 6 shows SEM images of $\mathrm{Cu}$ samples under different sintering conditions. The particle growth of the sintered sample with intermediate step at $200^{\circ} \mathrm{C}$ was bigger than the sample with intermediate step at $150^{\circ} \mathrm{C}$. The porosity within the sintered sample with $200^{\circ} \mathrm{C}$-step was less than that with $150^{\circ} \mathrm{C}$-step. Therefore, $200^{\circ} \mathrm{C}$ is the optimized removal temperature for organic materials before $\mathrm{Cu}$ powders get sintered.

Based on these results, the sample was sintered at $230^{\circ} \mathrm{C}$ with $200^{\circ} \mathrm{C}-1 \mathrm{~h}$ step and its electrical resistivity of the sample was measured to be $7.67 \times 10^{-8} \Omega \cdot \mathrm{m}$. This resistivity is comparable to the one sintered at $350^{\circ} \mathrm{C}$ for $4 \mathrm{~h}$. Moreover, Fig. 6 shows that the porosity of the sintered samples at $350^{\circ} \mathrm{C}$ for $4 \mathrm{~h}$ and at $230^{\circ} \mathrm{C}$ for $8 \mathrm{~h}$ is comparable whereas the porosity of the sintered sample with $150^{\circ} \mathrm{C}-1 \mathrm{~h}$ step seems to 
be high, indicating that organic materials were not completely removed at $150^{\circ} \mathrm{C}$ and resulted in separations among particles at sintering temperature. This indicates that the intermediate temperature for removal of binder is critical as well as its sintering temperature. Kang et al. reported that a conductive ink having 40 mass $\%$ copper when printed by inkjet gave a resistivity of $\left.3.67 \times 10^{-8} \Omega \cdot \mathrm{cm} .{ }^{17}\right)$ Cho et al. produced conductive nanoinks having 45 mass $\%$ copper that gave a resistivity of $4.0 \times 10^{-7} \Omega \cdot \mathrm{m}$ when inkjet-printed. ${ }^{18)}$ Compared to that, our study used a much lower copper content (10 mass\%) but gave a comparable resistivity $\left(5.69 \times 10^{-8} \Omega \cdot \mathrm{m}\right)$ when sintering was done in hydrogen atmosphere. This low temperature sintering result shows that ink jet printing and sintering on flexible substrate is possible.

\section{Conclusions}

$\mathrm{Cu}$ ink using 1-octanol solvent was synthesized and $\mathrm{Cu}$ patterns were made successfully. 1-Octanethiol was coated on the surface of CNPs for oxidation prevention, and the ink using these powders was prepared using 1-octanol as a solvent. The prepared ink was stable over 6 weeks as $\mathrm{CH}_{3}$ chain length of solvent dramatically affects the stability of dispersion. For sintering, an intermediate temperature at $200^{\circ} \mathrm{C}$ step was found to be the optimum temperature to remove organic materials before sintering compared to the sample with an intermediate temperature at $150^{\circ} \mathrm{C}$. The electrical resistivity of the sintered $\mathrm{Cu}$ powders with $150^{\circ} \mathrm{C}$ $1 \mathrm{~h}$ step was measured to be $2.63 \times 10^{-7} \Omega \cdot \mathrm{m}$ whereas the electrical resistivity of the sintered sample with $200^{\circ} \mathrm{C}-1 \mathrm{~h}$ step was measured to $5.69 \times 10^{-8} \Omega \cdot \mathrm{m}$. Moreover, SEM images for these samples show that grain growth and necking were much better for the sample with $200^{\circ} \mathrm{C}-1 \mathrm{~h}$ step than the one with $150^{\circ} \mathrm{C}-1 \mathrm{~h}$ step. Therefore, it was found that this step temperature for removing organic materials has a dramatic effect for sintering.

Electrical resistivity was measured to be $5.69 \times 10^{-8} \Omega \cdot \mathrm{m}$ for the sample sintered at $350^{\circ} \mathrm{C}$ for $4 \mathrm{~h}$ and $7.67 \times 10^{-8} \Omega \cdot \mathrm{m}$ for the sample sintered at $230^{\circ} \mathrm{C}$ for $8 \mathrm{~h}$. This result is almost similar to $5.4 \times 10^{-8} \Omega \cdot \mathrm{m}$ using $15 \mathrm{~nm}$-sized $\mathrm{Cu}$ powders according to the previous study. ${ }^{19)}$ Therefore, 1-octanethiol VSAMs and 1-octanol ink were used successfully for lowtemperature sintering process to fabricate conductive $\mathrm{Cu}$ patterns by finding optimum temperature of $200^{\circ} \mathrm{C}$ for complete removal of organic materials prior to sintering process.

\section{Acknowledgment}

The present work was carried out with the support of a Next Generation New Technology Development Program (Project No. 10030038) of the Korea Ministry of Commerce, Industry and Energy (MOCIE), by Basic Science Research Program through the National Research Foundation of Korea (NRF) funded by Ministry of Education, Science and Technology (2011-0029862) and by the Human Resources Development of the Korea Institute of Energy Technology Evaluation and Planning (KETEP) grant funded by the Ministry of Knowledge Economy, Republic of Korea (No. 20124030200130).

\section{REFERENCES}

1) T. Ito and S. Okazaki: Nature 406 (2000) 1027-1031.

2) Y. Lee, J. R. Choi, K. J. Lee, N. E. Scott and D. Kim: Nanotechnology 19 (2008) 415604.

3) B. K. Park, D. Kim, S. Jeong, J. Moon and J. S. Kim: Thin Solid Films 515 (2007) 7706-7711.

4) K. Salaita, Y. Wang and C. A. Mirkin: Nat. Nanotechnol. 2 (2007) 145155.

5) S. Hwang and Y. Kim: Kor. J. Met. Mater. 48 (2010) 1064-1069.

6) I. R. Kim, S. C. Hong and J. P. Jung: Kor. J. Met. Mater. 49 (2011) 388-395.

7) J. H. Kwon, S. Y. Park, T. H. Lee, J.-M. Yang and C. S. Lee: Appl. Surf. Sci. 257 (2011) 5115-5120.

8) J. Bharathan and Y. Yang: Appl. Phys. Lett. 72 (1998) 2660-2662.

9) T. Kawase, S. Moriya, C. J. Newsome and T. Shimoda: Jpn. J. Appl. Phys. 44 (2005) 3649-3658.

10) T. R. Hebner, C. C. Wu, D. Marcy, M. H. Lu and J. C. Sturm: Appl. Phys. Lett. 72 (1998) 519-521.

11) E. Tekin, P. J. Smith, S. Hoeppener, A. M. J. van den Berg, A. S. Susha, A. L. Rogach, J. Feldmann and U. S. Schubert: Adv. Funct. Mater. 17 (2007) 23-28.

12) R. A. Street, W. S. Wong, S. E. Ready, M. L. Chabinyc, A. C. Arias, S. Limb, A. Salleo and R. Lujan: Mater. Today 9 (2006) 32-37.

13) T. Y. Dong, H. H. Wu and M. C. Lin: Langmuir 22 (2006) 6754-6756.

14) M. R. Seong, J. H. Kwon, G. Y. Lee, D. K. Kim, Y. S. Kim and C. S. Lee: Appl. Surf. Sci. 256 (2010) 2332-2336.

15) M. R. Seong, G. Y. Lee, D. K. Kim, Y. S. Kim and C. S. Lee: Met. Mater. Int. 15 (2009) 963-966.

16) M. M. Haque, S. Y. Park, J. H. Her, J. H. Park and C. S. Lee: Electron. Mater. Lett. 7 (2011) 195-199.

17) J. S. Kang, H. S. Kim, J. Ryu, H. T. Hahn, S. Jang and J. W. Joung: J. Mater. Sci. Mater. Electron. 21 (2010) 1213-1220.

18) M. S. Cho, W. H. Choi, S. G. Kim, I. H. Kim and Y. Lee: J. Nanosci. Nanotechnol. 10 (2010) 6888-6891.

19) J. Cheon, J. H. Lee and J. Kim: Thin Solid Films 519 (2011) 30373042 . 